\title{
Right Homonymous Hemianopia: A Clinical Case Report of Schizencephaly
}

\author{
Arminda Neves Fausto Carvalheira Joana Campos Pedro Alfaiate \\ António Campos João Paulo Castro Sousa \\ Ophthalmology Department, Leiria Hospital Center, Leiria, Portugal
}

\section{Key Words}

Homonymous hemianopia $\cdot$ Schizencephaly

\begin{abstract}
Purpose: To report a case of a 56-year-old male with right homonymous hemianopia. Methods: Retrospective descriptive study of a case report based on information from clinical records, patient observation and analysis of complementary diagnostic tests. Results: An asymptomatic 56-year-old male presented to our hospital for a routine ophthalmic examination. The best-corrected visual acuity was 20/20 in the right eye (RE) and in the left eye (LE). Pupillary function, intraocular pressure, external segment examinations and slit-lamp biomicroscopy were normal, bilaterally. Fundoscopy showed a cup-to-disc (C/D) ratio in the RE of 0.3 and of 0.4 in the LE. Retinal nerve fiber layer (RNFL) thickness measured by spectral domain optical coherence tomography revealed thinning of the superior, temporal and nasal RNFL in the RE and thinning of the superior, inferior and temporal RNFL in the LE. Automated static perimetry showed right homonymous hemianopia. Brain computed tomography (CT) showed an open-lip schizencephaly with a significant reduction of the left brain parenchyma. Conclusions: Despite the large visual defect, the patient was unaware of it and had an active professional life. This is an interesting case because despite the extensive morphological abnormalities seen on brain CT there is a relatively small functional repercussion.
\end{abstract}


Neves et al.: Right Homonymous Hemianopia: A Clinical Case Report of Schizencephaly

\section{Introduction}

Schizencephaly is the most severe form of neuronal migration defects which develop between 2 and 5 months of gestation. It is characterized by the presence of a cleft in the brain extending from the surface of the pia mater to the cerebral ventricles. The margins of the cleft are lined with heterotropic, dysplastic gray matter, which is pathognomonic of the disease [1]. It was first described by Yakovlev and Wadsworth [2] in 1946 who divided the malformation in two types: type I (closed-lip) and type II (open-lip); however, there were reports of the disease in 1887 by Wilmarth [1]. It may be unilateral or bilateral, and $60 \%$ of the cases of unilateral schizencephaly are type II [3]. The estimated prevalence is 1.54 per 100,000 births [4].

The etiology of the disease is not well understood, but genetic and nongenetic etiologies have been postulated [5]. The role of genetics remains controversial, namely the gene EMX-2 [6] and COL4A1 mutations [7]. The severity of the clinical manifestations is usually related to the amount of brain affected by the abnormality [8]. Clinical features of this malformation include epilepsy, motor deficits and psychomotor retardation [1,9]. Magnetic resonance imaging (MRI) is the best imaging test because of its superior differentiation of anomalous gray matter along the cleft; however, computed tomography (CT) may be used as well. Secondary findings that can be identified are hydrocephalus, heterotopia, polymicrogyria, arachnoid cysts or corpus callosum dysgenesis [10].

The therapeutic management of schizencephaly is conservative and predominantly consists in treatment of epilepsy and rehabilitation of motor deficits and mental retardation. Surgical treatment is undertaken in complicated cases, like concomitant hydrocephaly or intracranial hypertension [1].

We report a case of a 56-year-old male with right homonymous hemianopia that was diagnosed with schizencephaly. It was an atypical clinical presentation that led us to the diagnosis of a very rare condition, and it is the first case report published in which the diagnosis of schizencephaly was made after an ophthalmological finding.

\section{Case Presentation}

An asymptomatic 56-year-old male presented to our hospital for a routine ophthalmic examination. The patient had congenital right hemiparesis and no other relevant medical history. He had a normal psychomotor development, without neurological disease, and a professionally active life; however, his work did not require uninterrupted spatial vision. There was no family history of congenital anomalies. The best-corrected visual acuity was $20 / 20$ in the right eye (RE) and in the left eye (LE). Pupillary function, intraocular pressure, external segment examination and slit-lamp biomicroscopy were normal. His color vision was normal as tested by the Ishihara test. Fundoscopy showed a cup-to-disc (C/D) ratio in the RE of 0.3 and in the LE of 0.4 and bilateral optic disc pallor (fig. 1). Retinal nerve fiber layer (RNFL) thickness measured by spectral domain optical coherence tomography revealed thinning of the superior, temporal and nasal RNFL in the RE and thinning of the superior, inferior and temporal RNFL in the LE (fig. 2). The automated static perimetry revealed right homonymous hemianopia, which was not noticed by the patient (fig. 3, left). Afterwards, he was referred to neuro-ophthalmological consultation and a brain CT showed an open-lip schizencephaly with a significant reduction of the left brain parenchyma and a left frontotemporal arachnoid cyst (fig. 3 , right). The patient was regularly followed up. 
Neves et al.: Right Homonymous Hemianopia: A Clinical Case Report of Schizencephaly

\section{Discussion}

The etiology of schizencephaly may be related to young maternal age, teratogens, prenatal infection or maternal trauma [5]. In our case, the age of the patient did not allow us to verify the gestation story; however, there was no history of congenital infections or maternal risk factors and the parents were phenotypically normal.

Motor deficits as clinical signs include hemiparesis in case of unilateral schizencephaly and quadriparesis in bilateral schizencephaly; psychomotor retardation is another clinical feature of this disease $[1,9]$. Our patient had congenital right hemiparesis, but no history of epilepsy or other neurological disease and no cognitive delay, which justifies the late diagnosis. The diagnosis of schizencephaly was made by CT scan. Despite the secondary findings that can be identified [10], in this case the patient only had a frontotemporal arachnoid cyst associated with type II schizencephaly.

The patient had a professionally active life and never noticed the clinically evident visual field loss; the fact that his work did not require uninterrupted spatial vision and the presence of right homonymous hemianopia since birth may explain that fact.

This is an interesting case, either because of the older age of the patient at the time of diagnosis and because the presentation of this congenital rare disorder consisted in an ophthalmological sign. Despite the extensive morphological abnormalities seen on brain CT, there was a relatively small functional repercussion, with a normal psychomotor development of the patient and a good quality of life. However, due to the imperceptible clinical visual findings that may be present in this disease (like large visual defects), which may influence the realization and safety of some activities like driving and tasks that require uninterrupted spatial vision, perhaps all patients with schizencephaly should be routinely examined by a neuro-ophthalmologist to properly characterize the clinical expression of schizencephaly.

In conclusion, our study represents an atypical clinical presentation of this rare condition diagnosed accidentally during a routine ophthalmic examination and no similar case reports have been published thus far. The ophthalmologist should be aware to detect subtle ophthalmological signs that can lead to the diagnosis of systemic diseases.

\section{Statement of Ethics}

The authors state that the subject of this article gave informed consent and the study protocol has been approved by the institute's committee on human research.

\section{Disclosure Statement}

The authors have no proprietary interests, financial support or other conflicts of interest to report.

\section{References}

1 Halabuda A, Klasa L, Kwiatkowski S, Wyrobek L, Milczarek 0, Gergont A: Schizencephaly-diagnostics and clinical dilemmas. Childs Nerv Syst 2015;31:551-556.

-2 Yakovlev PI, Wadsworth RC: Schizencephalies: a study of the congenital clefts in the cerebral mantle; clefts with fused lips. J Neuropathol Exp Neurol 1946;5:116-130. 
Case Reports in

Ophthalmology

\begin{tabular}{l|l}
\hline Case Rep Ophthalmol 2016;7:16-20 \\
\hline DOI: 10.1159/000443323 & $\begin{array}{l}\text { ○ } 2016 \text { The Author(s). Published by S. Karger AG, Basel } \\
\text { www.karger.com/cop }\end{array}$ \\
\hline
\end{tabular}

Neves et al.: Right Homonymous Hemianopia: A Clinical Case Report of Schizencephaly

3 Osborn AG, Salzman KL, Barkovich AJ: Schizencephaly; in Osborn Diagnostic Imaging Brain ed 2. Amirsys Publishing, Inc., chapt 1, 2010, pp 77-80.

4 Curry CJ, Lammer EJ, Nelson V, Shaw GM: Schizencephaly: heterogeneous etiologies in a population of 4 million California births. Am J Med Genet A 2005;137:187-189.

5 Dies KA, Bodell A, Hisama FM, Guo CY, Barry B, Chang BS, Barkovich AJ, Walsh CA: Schizencephaly: association with young maternal age, alcohol use, and lack of prenatal care. J Child Neurol 2013;28:198203.

6 Tietjen I, Bodell A, Apse K, Mendonza AM, Chang BS, Shaw GM, et al: Comprehensive EMX2 genotyping of a large schizencephaly case series. Am J Med Genet A 2007;143A:1313-1316.

7 Yoneda Y, Haginova K, Kato M, Osaka H, Yokochi K, Arai K, et al: Phenotypic spectrum of COL4A1 mutations: porencephaly to schizencephaly. Ann Neurol 2013;73:48-57.

$>8$ Liang JS, Lee WT, Peng SSF, Yu TW, Shen YZ: Schizencephaly: correlation between clinical and neuroimaging features. Acta Paediatr Taiwan 2002;43:208-213.

$\triangleright 9$ Barkovich AJ, Kjos BO: Schizencephaly: correlation of clinical findings with MR characteristics. AJNR 1992;13:85-94.

$\rightarrow 10$ Denis D, Chateil JF, Brun M, Brissaud O, Lacombe D, Fontan D, Flurin V, Pedespan J: Schizencephaly: clinical and imaging features in 30 infantile cases. Brain Dev 2000;22:475-483.
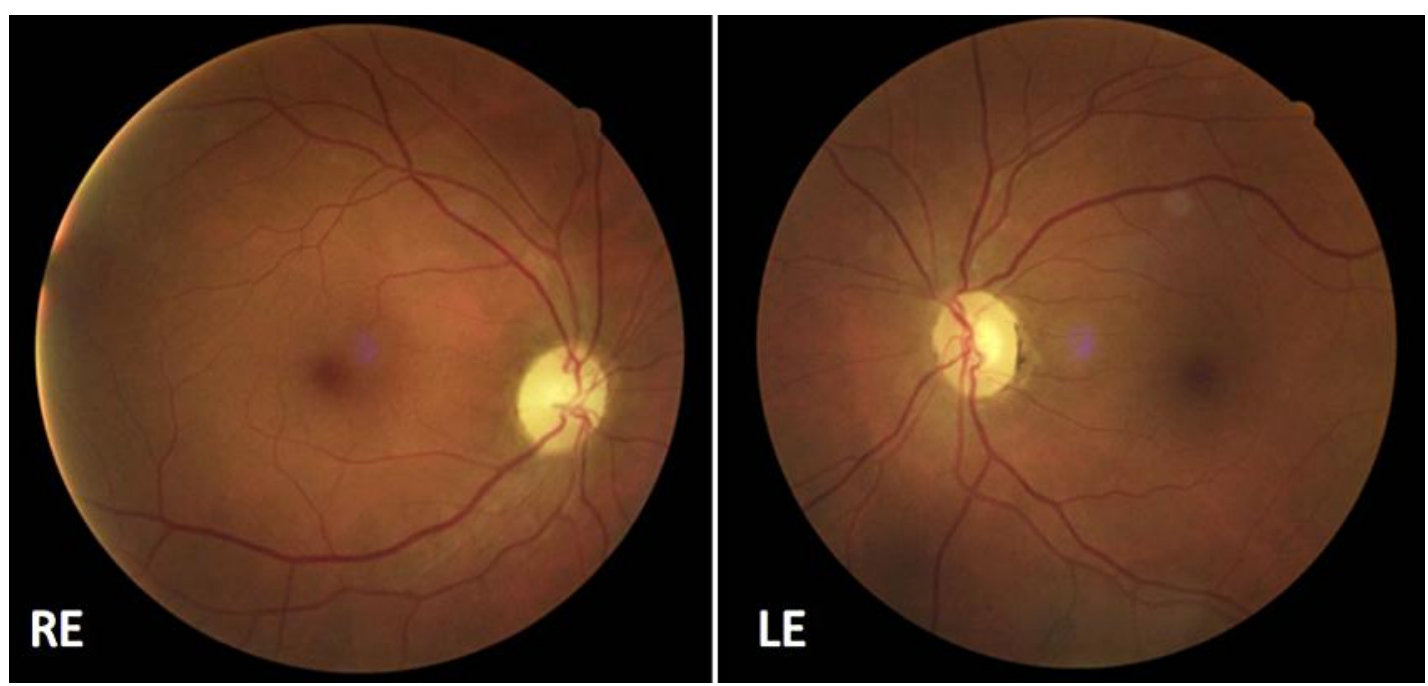

Fig. 1. Fundoscopy showed a C/D ratio of 0.3 in the RE and of 0.4 in the LE as well as bilateral optic disc pallor. 


\section{Case Reports in \\ Ophthalmology}

\begin{tabular}{l|l}
\hline Case Rep Ophthalmol 2016;7:16-20 \\
\hline DOI: 10.1159/000443323 & $\begin{array}{l}\text { ○ 2016 The Author(s). Published by S. Karger AG, Basel } \\
\text { www.karger.com/cop }\end{array}$ \\
\hline
\end{tabular}

Neves et al.: Right Homonymous Hemianopia: A Clinical Case Report of Schizencephaly
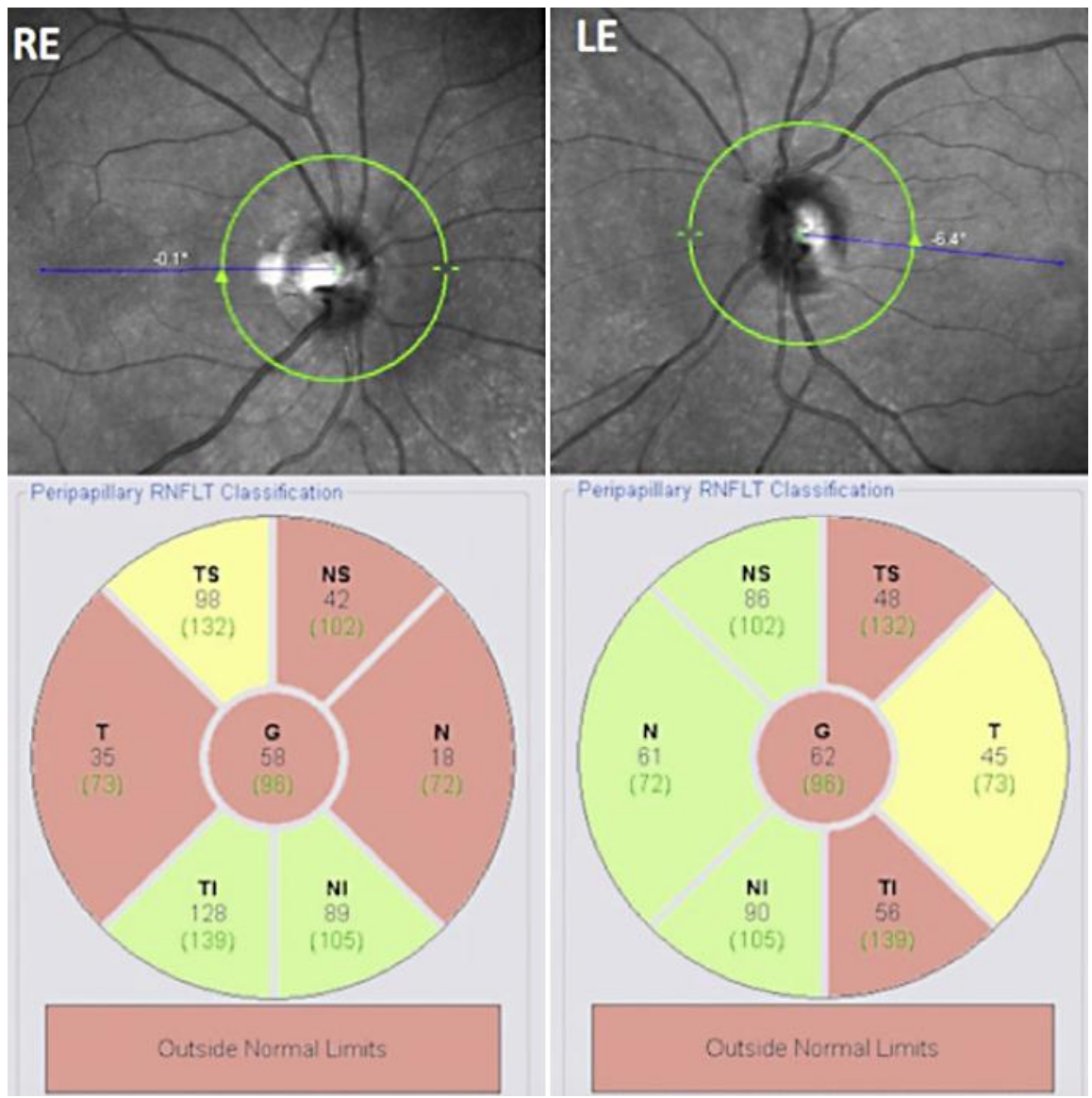

Fig. 2. Spectral domain optical coherence tomography of the RNFL revealed thinning of the superior, temporal and nasal RNFL in the RE and thinning of the superior, inferior and temporal RNFL in the LE.
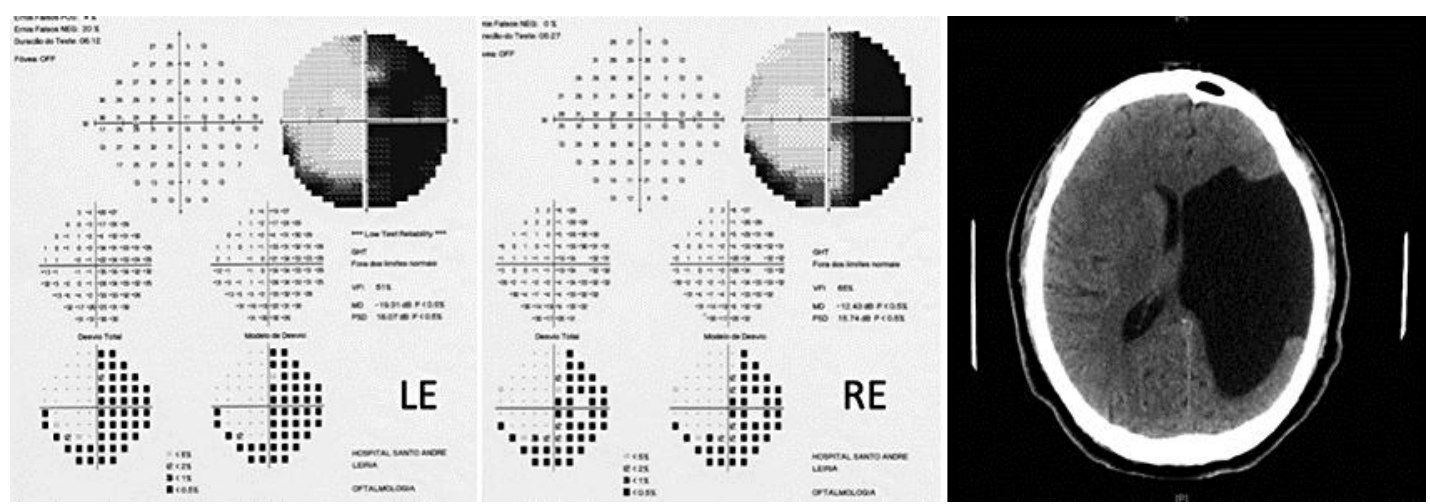

Fig. 3. Automated static perimetry (30-2) showed right homonymous hemianopia (left). Brain CT showed an open-lip schizencephaly and a frontotemporal arachnoid cyst (right). 